\title{
A renewed search for meaning?
}

\author{
Bjørn Stensaker \\ Universitetet i Oslo
}

The responsible university - exploring the Nordic context and beyond (2019). Sørensen, Mads, Geschwind, Lars, Kekäle, Juoni \& Pinheiro, Rómulo (eds.) PalgraveMacmillan (Open access). https://10.1007/978-3-030-25646-3

Those familiar with higher education research are well aware of a special genre in the literature dealing with the future challenges and prospects of the university. Prof. Ronald Barnett is perhaps the godfather of this genre, offering a steady stream of critical reflections on this topic over the years. The development and global recognition of the UN's Sustainable Development Goals (SDG) can be said to have further spurred critical reflections on the role of the university for societal development - beyond the contributions to economic growth. The Responsible University is the latest addition to this genre - edited by established higher education scholars from the Nordic countries.

The editors also use the Nordic region as a rationale for the book as they highlight the Nordic region as an interesting setting for studying responsibility in higher education, not least based on claims concerning how the countries in the region are often perceived as taking responsibility not only for their own citizens and societies but also for those on the outside.

As a project, the book is indeed more explorative than normative, and a key theme throughout the volume is how we can understand and interpret responsibility, and how these interpretations relate to higher education institutions. This explorative purpose has led to chapters on the history and current societal dynamics driving responsibility to the top of agendas in both the public and the private sector; chapters dealing with "responsible" innovation activities, and chapters on how to organize for responsibility. While the structuring of these chapters into sections certainly makes sense, this reader was left a bit puzzled as to the selection and topics addressed. Thus, it is perhaps not surprising that the authors in their introductory chapter are rather silent on how the different chapters fit the responsibility agenda sketched.

However, as an exploration into responsibility and the possible meanings of what it takes to be a responsible university, the book offers a number of interesting contributions. Paul Benneworth's chapter on irresponsible behavior of universities and his insight that such behavior should be considered as a public value failure and not as a market failure is indeed noteworthy and interesting. The discussion on the responsible university certainly needs to be broader than the standardized critique of neo-liberal reforms and the unintended consequences of new public management in higher education, and this chapter adds to our thinking in this area.

Another interesting example where high expectations have (so far) led to moderate results is reported in the chapter by Linda Barman and her colleagues, where they analyze how the MOOC phenomenon has affected three universities, and how the ambition of MOOCs as a form of open access education have been realized. Their argument that MOOCs may have

Correspondence: bjorn.stensaker@iped.uio.no

Artiklar och reflektioner är kollegialt granskade. Övriga bidragstyper granskas av redaktionen. Se https://hogreutbildning.se ISSN 2000-7558

(C)2020 Bjørn Stensaker. This is an Open Access article distributed under the terms of the Creative Commons Attribution-NonCommercial 4.0 International License (https://creativecommons.org/licenses/by-nc/4.0/), allowing third parties to share their work (copy, distribute, transmit) and to adapt it, under the condition that the authors are given credit, that the work is not used for commercial purposes, and that in the event of reuse or distribution, the terms of this license are made clear.

Citation: Stensaker, B. (2020). "A renewed search for meaning?", Högre utbildning, 10(2), 73-74. https://doi.org/10.23865/hu.v10.2666 
limited implications for folk-bildung [folk-education], and that the uses of MOOCs may be far more limited and far less oriented towards open access than those initially advocating this innovation argued, is very much in line with the evidence gathered so far, and demonstrates that facilitating responsibility is highly dependent on rather trivial issues, such as funding, the design and access of digital platforms, governance, etc.

A contribution that looks even more closely into factors conditioning responsibility is offered by Jouni Kekäle and Jenni Varis, where they look into how university leadership and human resources could be aligned to the idea of a more responsible university. Based on the assumption that responsible behavior is closely linked to the commitment and motivation of staff, they argue that autonomy and diversity of staff are key factors fostering such commitment and motivation. While this certainly makes sense, it also opens up for interesting questions as to the extent that responsibility can be strategically "designed" and the role of the leadership in this process.

In the concluding chapter, the editors elaborate on the analytical eclecticism characterizing the book, and advocate for the need of a more organizational perspective in taking the vision and ambitions of a more responsible university forward. Such a perspective certainly makes sense, not least acknowledged by the earlier claims made by the editors that the transformation into a more responsible mode is highly dependent on some sort of coordination between the national authorities, the higher education institutions, the departments and research groups within the institutions, and the individuals working there. However, the use of broader insights from the study of organizations and organized fields also allows the editors to take a more nuanced stand on one of the key questions the books set out to explore: How can we interpret the idea of the responsible university? Their tentative response to this question is that there are at least five different possible perspectives one could apply: Responsibility as a strategic choice for the institutional leadership; responsibility as a tradition and moral duty; responsibility as mere window dressing; responsibility as a global meta-idea which is difficult to reject; and responsibility as resilience - where the ability of universities to overcome and incorporate a steady stream of new ideas and expectations into the organization is acknowledged.

Put together these perspectives certainly offer a useful heuristic for the many different ways universities may respond to the idea of the responsible university, ranging from the more cynical approaches to more deliberate, or even more unstructured, attempts at change. The perspectives may also be combined, and this reviewer would argue that it is a pity that the editors do not pursue and elaborate more on these perspectives in the concluding reflections. Resilience perspectives could, for example, open up for interesting implications of whether "doing nothing" could actually be interpreted as responsible behavior if this reduces the risk of irresponsible institutional initiatives? If the responsible university is the next emerging global meta-idea, it could also be used more strategically by universities to transform existing accountability regimes - perhaps eliminating the sharp distinction between the environmental determinism that seems to embed many universities and the strategic room to maneuver that follows from a more manageable university? Given the long tradition for pragmatism, dialogue and negotiation that exists in the Nordic region, further investigations on how to make sense of this concept should certainly be launched, looking into whether there are feasible alternatives to the dominating narrative of being world-class. A foundation for such further studies has been made with this volume - the next step is perhaps to go from single case studies to more comparative research designs.

Prof. Bjørn Stensaker

University of Oslo 